\title{
Marital Rape; A Myth or Fact?
}

\section{Huzaifa Sarfaraz}

University of Karachi

Corresponding Author Email: huzaifa.socio@gmail.com

Marital rape is one of the serious issue in all over the world. Marriage is a relationship where things are better worked when they are in mutual understanding and acceptance; any deed which is with force or without consent is considered unfair. Likewise, forced sex with spouse or to demand sex without consent is considered as marital rape, but still in many countries and culture it is not considered any serious issue, moreover this topic is considered a taboo which should not be discussed inside or outside of the family. Marital rape is a concept that many find difficult to comprehend. Legal definitions of rape vary from state to state. The definition of marital rape is complicated further by the fact that forced sex may not be considered a crime in marriage. In order to study this question in more detail; clear definition of marital rape is required and women should be asked questions about the activities defined as rape-without using the "rape" label (Frieze, 1983). A multi-country study was conducted by World Health Organization on women's health and domestic violence against women, which reported that reported prevalence of physical violence by intimate partners ranged from $23 \%$ to $49 \%$ and that of sexual violence between $10 \%$ and $50 \%$ (Garcia-Moreno, Jansen, Ellsberg, Heise, \& Watts, 2005). According to CNN's report marital rape is legal in India, Bahamas, Lebanon, Singapore, Palestinian territories and Malta (CNN edition, 2015). In Pakistan also, there is no direct law regarding coercive sex which can protect women from being raped by their own partners (Patel, 2003). In a newspaper's survey, Julie Doron reported that 7 percent of the respondents experienced marital rape, while fewer than 1 percent of the respondents were general rape victims (Doron, 1980). Diana Russell claimed in her study that 12 percent of the married women in a random sample of San Francisco women had experienced some form of forced sex in marriage (Russell, 1980). These studies have proved that marital rape is a serious problem which is needed to be discussed and argued. One thing also becomes clear from results of the presented studies, that women are the most who become victim of this misery; as it has been also discussed in previous studies that for married women sex is not always wanted and when forced sex is made by men; it comes under the umbrella of rape.

There are many reasons which are found responsible for providing space to marital rape; one of the most important factor is traditional gender norms that equate masculinity with toughness and dominance and femininity with submissiveness and this place married young women at greater risk of unwanted sexual experiences. Education of female is also considered as an important agent in this issue; as studies have also proved that risk of frequent unwanted sex declines as years of schooling increases; including the household economic pressure which is directly related to sexual coercion and religion is also found to be correlated with unwanted sex (Santhya, 2007). Non-consensual sex is also used as a form of domestic violence over women (Fikree, Razzak, \& Durocher, 2005). International Clinical Epidemiology Network conducted a survey in India; country with which Pakistan shares same norms and culture, found that $26 \%$ of married women had experienced physical violence in and nearly $15 \%$ of the total sample reported one or more incidents of forced sex.

Elaine Hilberman and Kit Munson reported that sexual assaults were common part of marital violence and many of the women in their study described being beaten and raped in front of their children (Hilberman \& Munson, 1977). It is true that both physical violence and rape involve, though in an extreme form, traits of aggression, dominance, and physical strength which our culture tends to value generally for men (Lederer, 1968). 
Serious gender inequalities and human rights violation against women is present in Pakistan along with restrictions and limitations of autonomy. In a report by Asian Pacific Institute on Gender-Based Violence it was mentioned that $64 \%$ of Indian and Pakistani women had experienced sexual violence by an intimate partner.

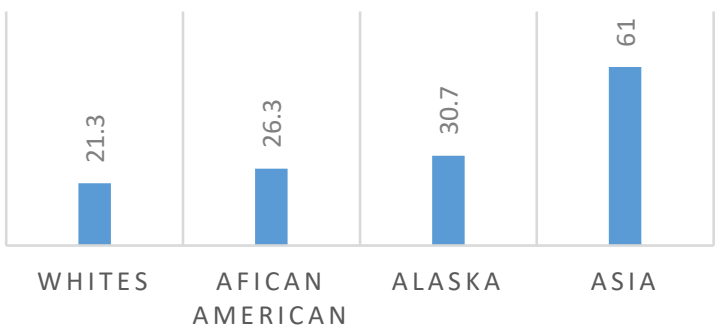

Fig 1: API Survey on Domestic Violence (2015) In a study which was published by Ali, et al., in 2007, stated that in Pakistan men are the primary authority and women are their sub-ordinates; men hold superior position as compare to females; adding that women routinely face gender based inequalities in and outside their homes and are confined for doing house work for their families. They also highlighted unselfish, calmness, tolerance and hospitality as characteristics of good women which are directed by education, mass media and culture of society; adding that woman who sacrifices her dreams and desires for her family is supposed to be the good one as compared to the one who speaks for her rights and a good man is expected to be a good advisor, fair decision maker, strong and financially stable with good leadership qualities. Culture plays a pivotal role in molding these gender roles and education and mass media are prominent agents of change, the reasons that young generation of Pakistan is positive towards the modernization of gender roles (Ali, 2011).

Another persuasive argument is that many families continue to maintain the ideology that values the husband's authority, emphasizes respect for parents, and stresses differences between men and women, all of these in the face of considerable changes in actual behavior (Lamphere, 1989). Many researchers have also concentrated stress and its relationship with work force. Housewives report that they feel no authority at home, they are not allowed to take any decision for themselves and on other family issues and the nature of house job is unrewarding (Radloff, 1975). Ferree (1979) also affirmed that fulltime housewives feel themselves dissatisfied and in worse conditions as compare to the working wives, because work of housewife lack sense of competence, social connectedness and self-determination and their opinions are also not valued due to their lack in financial contribution in family, this leads to sense of powerlessness, this is why fulltime housewives report more issues of anxiety and stress than women with paid jobs; he added that paid employment of women can at least help them relief from problems of powerlessness, meaninglessness and social isolation.

Boyd (1989) stated that children learn sex roles from opposite genders as well as same sex adults but theories suggest that girls learn from their mothers; they take their mothers as role models. Women are more likely to hold their certain positions than men that is the reason that girls are more like their mothers than sons as their fathers. Females reported more influence by their mothers and a mother's encouragement towards education and profession effects girls more than a father's encouragement; and that non-traditional jobs are more valued for girls by both parents (Brogan \& Kutner, 1976). Basile (2002) found in his study that $61 \%$ of women who had become victim of unwanted sex with their spouse did so because of a sense of obligations.

In 2000, a cross-sectional survey was conducted in South Carolina for assessment of lifetime victimization of intimate partner violence (IPV) and forced or coerced sex and the help seeking behavior of victims. Results showed that among women, $25.3 \%$ experienced IPV (sexual, physical, or emotional violence) compared with $13.2 \%$ of men. Although women were significantly more likely to report physical or sexual IPV (17.8\%) than were men (4.9\%), men $(8.3 \%)$ were as likely as women $(7.4 \%)$ to report perceived emotional abuse without physical or sexual IPV. One half of men and women with annual incomes $<\$ 15,000$ reported IPV. Among women experiencing physical or sexual IPV, $53 \%$ sought community-based or professional services for IPV; women with higher education 
levels and those experiencing more severe violence were most likely to seek services. This study concluded that, IPV is common and that most victims do not receive services to address this violence (Coker, Derrick, Lumpkin, Aldrich \& Oldendick, 2000).

The topic of marital rape is one of the serious issues which is affecting the lives of women worldwide. Cultural believes and practices are the main reasons behind the misconception and ignorance of this issue Bennice \& Resick (2003). Due to cultural obligations, still today people consider marital rape less serious issue as compare to rape by stranger (Whatley, 2005). Due to cultural hindrances no good and validated data is available on the topic, because people; even victims do not provide accurate data which is making it more difficult for researchers to study and find solutions regarding this problem.

\section{References}

- Ali, T. S., Krantz, G., Gul, R., Asad, N., Johansson, E., \& Mogren, I. (2011). Gender roles and their influence on life prospects for women in urban Karachi, Pakistan: a qualitative study. Global health action, 4.

- Asian pacific institute on gender-based violence. (2015). Statistics on Violence against Api Women. Retrieve from https://www.api-gbv.org/aboutgbv/statistics-violence-against-api-women/.

- Basile, K. C. (2002). Prevalence of wife rape and other intimate partner sexual coercion in a nationally representative sample of women. Violence and Victims, 17(5), 511-524.

- Brogan, D., \& Kutner, N. G. (1976). Measuring sexrole orientation: A normative approach. Journal of Marriage and the Family, 38(1), 31-40.

- Coker, A. L., Derrick, C., Lumpkin, J. L., Aldrich, T. E., \& Oldendick, R. (2000). Help-seeking for intimate partner violence and forced sex in South Carolina. American journal of preventive medicine, 19(4), 316-320.

- Doron, J. (1980, August). Conflict and violence in intimate relationships: Focus on marital rape. In American Sociological Association Meeting, New York, August.
- Fikree,, Razzak, J., \& Durocher, J. (2005). Attitudes of Pakistani men to domestic violence: A study from Karachi, Pakistan. International Journal on Men's Health and Gender, 2, 49-58.

- Frieze, I. H. (1983). Investigating the causes and consequences of marital rape. Signs, 8(3), 532-553.

- Garcia-Moreno, C., Jansen, H., Ellsberg, M., Heise, L., \& Watts, C. (2005). WHO multi-country study on women's health and domestic violence against women: Initial results on prevalence, health outcomes and women's responses. Geneva: World Health Organization.

- Hilberman, E., \& Munson, K. (1977). Sixty battered women. Victimology, 2(3-4), 460-470.

- International Clinical Epidemiology Network [INCLEN]. (2000). Domestic violence in India: A summary report of a multi-site household survey. Washington, DC: International Centre for Research on Women (ICRW).

- Lamphere, L. (1986). From working daughters to working mothers: production and reproduction in an industrial community. American Ethnologist, 13(1), 118-130.

- Lederer, W. (1968). The Fear of Women. England: Oxford.

- Monica Sarkar and Inez Torre. (2015). Marital rape: Where in the world is it legal?. Retrieve fromhttp://edition.cnn.com/2015/03/05/asia/gallery/ marital-rape/index.html.

- Patel, R. H. (2003). Woman versus man: Socio-legal gender inequality in Pakistan. Karachi: Oxford University Press.

- Radloff, L. (1975). Sex differences in depression. Sex roles, 1(3), 249-265.

- Russell, D. (1980, August). The prevalence and impact of marital rape in San Francisco. In annual meeting of the American Sociological Association, New York.

- Santhya, K. G., Haberland, N., Ram, F., Sinha, R. K., \& Mohanty, S. K. (2007). Consent and coercion: Examining unwanted sex among married young women in India. International Family Planning Perspectives, 33(3), 124-132.

-Whatley, M. (2005). The effect of participant sex, victim dress, and traditional attitudes on causal judgements for marital rape victims. Journal of Family Violence, 20, 191-200. 